\title{
Effect of Miswak on Oral Health
}

\author{
Karama M. T. Al - Nuaimy \\ Department of Basic Sciences / College of Dentistry \\ University of Mosul
}

Received

18 / 04 / 2011
Accepted

26 / 06 / 2011

\begin{abstract}
الخلاصة
أجريت هذه الدراسة السريرية لمقارنة بين استخدام السواك أو فرشاة الأسنان من حيث الهئ

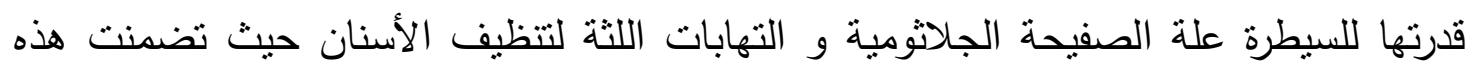

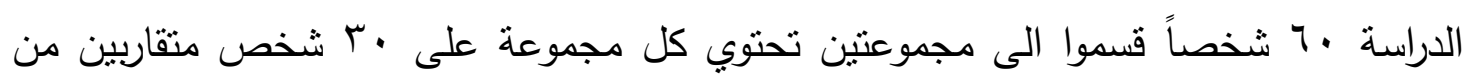

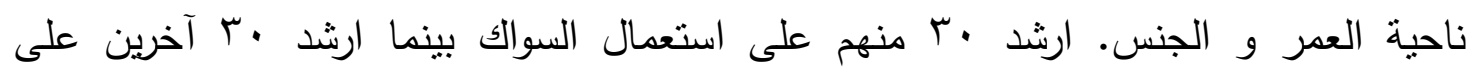

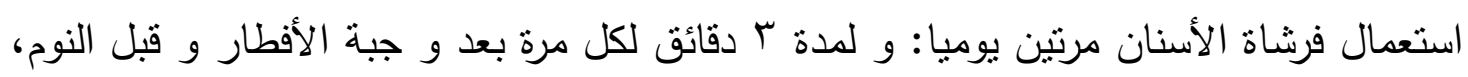

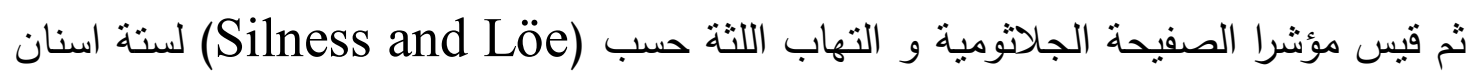

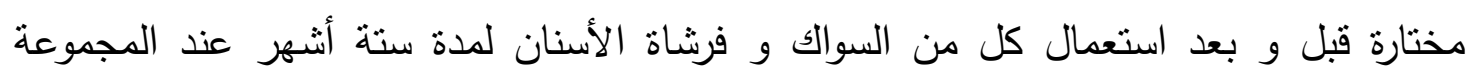
الأولى و المجموعة الثنانية.

أظهرت نتائج هذه الدراسة وجود اختلاف معنوي عند مستوى معنوية ه ٪ عند استخدام السواك عنه عند استخدام فرشاة الأسنان لمؤشر الصفيحة الجلاثومية و التهاب اللثة. ان نتائج هذه الدراسة تؤيد استخدام السواك للحصول على صحة أعلى للثة و الأسنان.
\end{abstract}

\section{ABSTRACT}

This clinical investigation was undertaken to compare the use of miswak or tooth brush to assess their ability to control plaque and gingival inflammation. In this clinical trail 60 subjects divided into two groups; each containing 30 persons matched in age and gender, 30 of them were instructed to use miswak while other 30 instructed to use tooth brush twice daily for 3 minutes after breakfast and before the bed time. The plaque and gingival indices were measured according to Silness and Löe for the six teeth at the base line and six months after use miswak in first group and second group.

The results of the study revealed that there is a significant reduction at $p<0.05$ when use miswak than use tooth brush for plaque and 
gingival index. The results of this study indicate use of miswak to obtain good oral health for gingival and teeth.

Key Words: Miswak, Chewing Stick, Oral health.

\section{INTRODUCTION}

Miswak or chewing stick or Siwak or Arak, means massage with a hard object; it is a root of selected plant which called "Arak" ${ }^{\text {(1) }}$ is a small tree with a crooked trunk, the roots are spongy and easy to crush between teeth. ${ }^{(2)}$

Chewing sticks are used by Muslims as a religious ritual in addition to teeth cleaning it is highly recommended and encouraged by the Prophet Islam. $^{(1,3)}$

The beneficial effects of miswak in oral hygiene and dental health to reduce the dental caries and periodontal diseases, it effects on plaque and gingival inflammation, this due to contain trimethylamine, an alkaloid salvadorine chlorides, high amount of fluoride, vitamin C, silica, sulpher, flavenoids and sterols.

There are various plants used as chewing sticks. In Africa the lime tree (citrus aurantafolia) and orange tree (citrus siness); while the roots were used by Black Americans as were those of (citrus sieberian bu). In India, a tree called Neen (azadrichta indica) and it is used in treatment of syphilis. $^{(1,6)}$

Miswak is often used to prevent oral habits such as smoking and thumb sucking. It can also be used in the development of dentition during eruption. $^{(2,3)}$

This study was done to investigate the effect of miswak on oral health for controlling the plaque formation and gingival inflammation.

\section{MATERIALS AND METHODS}

Sixty subjects were participated in this work their age ranged between $(20-35)$ years with mean of age equal $24 \pm 2$ years, who attending to Periodontic Department in Dentistry College of Mosul University and also from dental clinic; 30 of them give on instruction in the used of miswak instead of tooth brush 2 times daily for 6 months, the other (30) subjects used tooth brush only.

The plaque and gingival indices were measure according to Silness and Löe at $(1963)^{(7)}$, for both tooth brush and chewing stick using then the results for gingival index were recorded as occurance of gingivitis: Grade 1 (mild inflammation, slight change in colour, slight osedema, no bleeding on probing), Grade 2 (moderate inflammation, redness, oedema and glazing, the gum bleeds on probing), Grade 3 (severe inflammation, marked redness and oedema, ulceration, there is a tendency for spontaneous bleeding) or as absence of gingivitis, Grade 0 (normal gingival). 
For plaque index, the estimation of plaque accumulation in the same as for gingival index where the presence of plaque were given: Grade 1 (a film of plaque adhering to the gingival margin and the adjacent area of the tooth, the plaque may only be recognized by running a probe a cross the tooth surface), Grade 2 (a moderate accumulation of soft deposits within the gingival pocket or on the tooth and gingival margin, this can be seen with the marked eye), Grade 3 (an abundance of soft matter within the gingival pocket or on the tooth and the gingival margins) and absence of plaque gives, Grade zero (no plaque in the gingival area).

The subjects were divided into two equal groups: each consisted of thirty subjects. The first, they were received instructions to miswak two times daily for a period of 6 months, one at morning after breakfast and once at the evening before bed time. At second, they were received instructions to brush their teeth two times daily for a period of 6 months using the same tooth paste (Bio - Fresh K). They were instructed to brush for at least $3 \mathrm{~min}$. to ensure cleaning of the teeth, then rinse his mouth with no any intake of food or drink for $30 \mathrm{~min}$. post washing. The same regimen was done for two groups.

Before and after six month the gingival and plaque indices were measured for both groups in the same method mentioned above.

Statistical analysis of data in this study was mean \pm standard deviation (SD), and one way analysis of variance (ANOVA) among the two groups.

\section{RESULTS}

The results showed that subjects used miswak had significantly reduction in plaque index when compare with before using miswak or with after using tooth brush (Table 1, Figure 1). Also the results showed that subjects using tooth brush had significantly higher plaque and gingival indices before used tooth brush and after when compare with subjects used miswak (Table 2, Figure 2).

\section{DISCUSION}

This study is a clinical attempt to make a comparison for miswak used and tooth brush for control of oral health, only a few studies have been reported on the cleaning effectiveness of chewing sticks.

Whomsky LE and Sote, showed that the prevalence of dental caries was less among miswak users than users of tooth brush ${ }^{(6)}$, this agreed with results. The effect of miswak in reduce prevalence of dental caries due to chemical composition of miswak in contain Limonoid which consider antimicrobial effect against gram positive and gram negative micro-organisms ${ }^{(6-8)}$.

The positive effect of miswak on dental caries is also due to contain a reasonable amount of fluoride which protect the enamel surface from the caries in susceptible site such as pit, fissure and interproximal area $^{(8-10)}$. 
Shapiro W.B. and Kaslick R.S. found reduce in gingivitis in subject used miswak than subject used tooth brush ${ }^{(2,3)}$, and agreed with our study this attributed to effect could be on reduction of plaque and calculus formation due to chemical composition, which lead to reduction in bleeding gums ${ }^{(11,12)}$.

\section{CONCLUSION}

The miswak is a good alternative to tooth brush since it is inexpensive and readily available, it contains many medical properties, therefore it is important an effective as a tool for oral hygiene, it contain a potential value in reducing plaque, calculus and gingival inflammation and caries.

\section{REFERENCES}

1) Mostehy MR, Jassem AA and Yassin IA. Miswak as an oral health device preliminary chemical and clinical evaluation. 1983; 26: $41-$ 50 .

2) Hattab FN. Miswak, the natural tooth brush. J Clin Dent. 1997; 8: $125-129$.

3) Khoory $\mathrm{T}$. The use of chewing sticks in preventive oral hygiene. Clin Prevent Dent. 1983; 5(4): 11 - 14.

4) Hill CM, Gibson A. The oral and dental effects of chewing. Oral Surg Oral Med Oral Pathol. 1987; 63: 433 - 436.

5) Vlim KJ, Helwig E, Ahrens G. Fluoride taken up by plaque by the understand lying enamel and by clean enamel from three fluoride compounds in vitro. Caries Res. 1987; 16: 151 - 161.

6) Wohmsky LE, and Sote EO. Isolation of natural plaque inhibiting substances from Nigerian chewing sticks. Caries Res. 1984; 8: 216 -225 .

7) Le H. The gingival index, the plaque index and the retention index systems. J Periodontol. 1967; 38: 38 - 44.

8) Johansson I. The effect of chewing sticks on saliva composition. $J$ Nutr. 1998; 124: 210 - 220.

9) Masster M. and Schour I. Relation of malnutrition with dental florousis and oral hygiene to the prevalence and severity of gingivitis. $J$ Periodontol. 1975; 23: $215-218$.

10) Mengel R, Eigenbrodt $M$, Schunemann $T$. Periodontal status of a subject sample of Yemen. J Clin Periodontol. 2004; 31: 437 - 443.

11) Sha[iro WB and Kaslick RS. The influence of miswak on plaque, calculus and chronic gingival inflammation. J Periodontol. 1987; 54: $132-141$.

12) Adugna $F$, Jira $C$, Molla $T$. Khat chewing among Agaro secondary school students, Agaro, South Western Ethiopia. Ethiop Med J. 2008; 46: 161 - 168 . 
Karama M. T. Al - Nuaimy

Table (1): Mean \pm S.D values and C.V \% of plaque index of two groups

\begin{tabular}{|c|c|c|c|c|c||}
\hline Subject & Number & $\begin{array}{c}\text { Before } \\
\text { Mean } \pm \text { S.D }\end{array}$ & $\begin{array}{c}\text { After } \\
\text { Mean } \pm \text { S.D }\end{array}$ & C.V\% & p-value \\
\cline { 1 - 5 } With miswak & 30 & $5.2 \pm 0.16$ & $2.12 \pm 0.19$ & 8.96 & \multirow{2}{*}{$\leq 0.05$} \\
\hline With tooth brush & 30 & $4.8 \pm 0.18$ & $4.01 \pm 1.22$ & 30.42 & \\
\hline
\end{tabular}

C.V $=$ Coefficient of Variability

S.D $=$ Standard deviation

Table (2): Mean \pm S.D values and C.V \% of gingival index of two groups

\begin{tabular}{|c|c|c|c|c|c||}
\hline Subject & Number & $\begin{array}{c}\text { Before } \\
\text { Mean } \pm \text { S.D }\end{array}$ & $\begin{array}{c}\text { After } \\
\text { Mean } \pm \text { S.D }\end{array}$ & C.V\% & p-value \\
\cline { 1 - 5 } With miswak & 30 & $8.1 \pm 1.20$ & $3.21 \pm 1.81$ & 56.38 & \multirow{2}{*}{$\leq 0.05$} \\
\hline With tooth brush & 30 & $7.7 \pm 1.63$ & $6.15 \pm 1.73$ & 28.13 & \\
\hline
\end{tabular}

C.V $=$ Coefficient of Variability

S.D $=$ Standard deviation

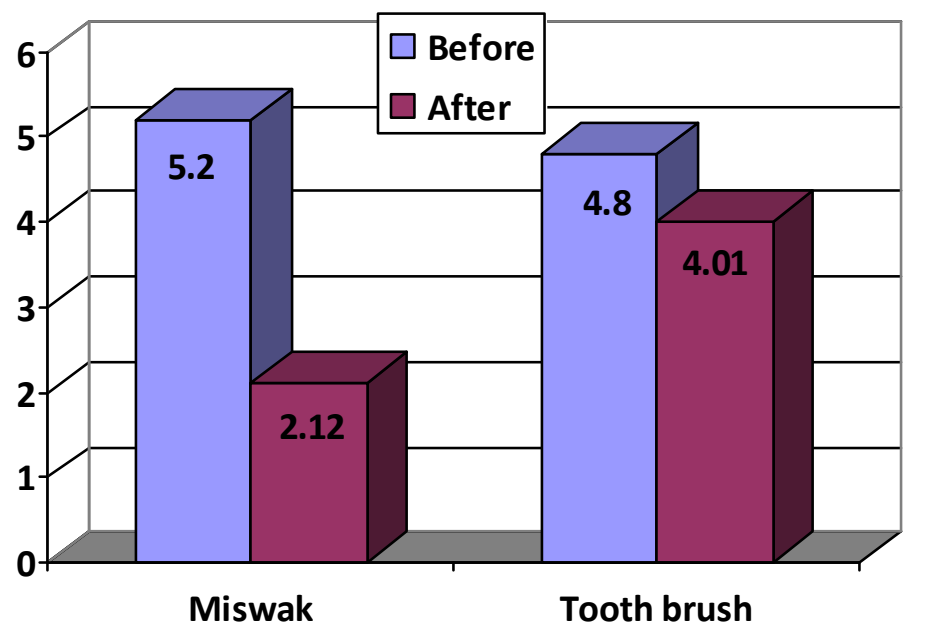

Figure (1): The plaque index for two groups before and after treatment

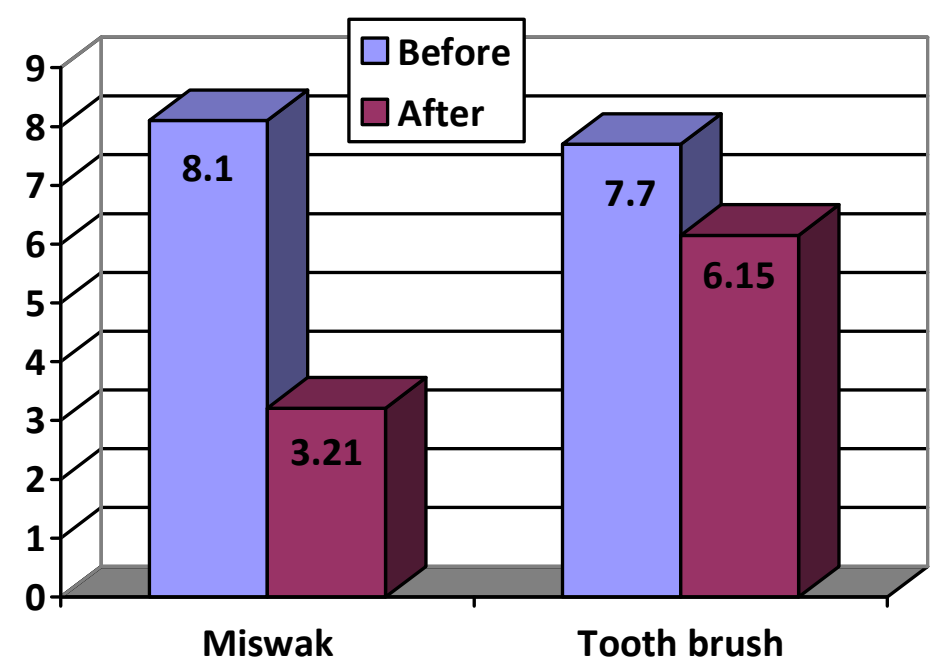

Figure (2): The gingival index for two groups before and after treatment 